\title{
BRPKM
}

Buletin Riset Psikologi dan Kesehatan Mental

http://e-journal.unair.ac.id/index.php/BRPKM

e-ISSN: 2776-1851

ARTIKEL PENELITIAN

\section{Hubungan antara Personal Relative Deprivation dengan Materialisme pada Emerging Adulthood}

INDRA WAHYU PRATAMA \& ILHAM NUR ALFIAN*

Fakultas Psikologi Universitas Airlangga

\begin{abstract}
ABSTRAK
Tujuan dari penelitian ini adalah untuk mengetahui hubungan antara personal relative deprivation dan materialisme. Deprivasi relatif di ukur dengan teori yang dikembangkan dari Crosby dan Materialisme diukur dengan teori yang dikembangkan oleh Dittmar. Partisipan dalam penelitian ini adalah emerging adulthood dengan rentang usia 18-25 tahun. Metode penelitian menggunakan kuantitatif dengan menggunakan survei melalui google form. Dalam menganalisis data menggunakan SPSS 25 for windows. Berdasarkan analisis terdapat hubungan positif yang signifikan antara personal relative deprivation dan materialisme, dengan nilai signifikansi sebesar 0,00. Nilai koefisien korelasi yang berada di angka 0.360 menunjukan bahwa hubungan antar variabel sedang.
\end{abstract}

Kata kunci: emerging adulthood, materialism, personal relative deprivation

\section{ABSTRACT}

The purpose of this study was to determine the relationship between personal relative deprivation and materialism. Personal relative deprivation measured by the theory developed from Crosby and Materialism measured by a theory developed from Dittmar. Participants in this study were emerging adulthoods with an age range of 18-25 years. The research method uses quantitative research type with data collection tools using a survey via google form. In analyzing data using SPSS 25 for windows. The results of the analysis showed that there was a significant positive relationship between personal relative deprivation and materialism. The correlation coefficient value which is at 0.360 indicates that the relationship between variables is moderate.

Keywords: emerging adulthood, materialism, personal relative deprivation

Buletin Penelitian Psikologi dan Kesehatan Mental (BRPKM), tahun, Vol. X(no), pp,

*Alamat kopartisipansi: Fakultas Psikologi Universitas Airlangga, Kampus B Universitas Airlangga Jalan

Airlangga 4-6 Surabaya 60286. Surel: ilham.nuralfian@psikologi.unair.ac.id

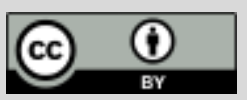

Naskah ini merupakan naskah dengan akses terbuka dibawah ketentuan the Creative Common Attribution License (CC-BY-4.0) (http://creativecommons.org/licenses/by/4.0), sehingga penggunaan, distribusi, reproduksi dalam media apapun atas artikel ini tidak dibatasi, selama sumber aslinya disitir dengan baik. 


\section{PENDAHULUAN}

Perpindahan tahapan perkembangan menimbulkan ketidakstabilan pada diri individu, bahkan dapat dikatakan bahwa fase dewasa awal merupakan masa yang paling tidak stabil di dalam perjalanan hidup seseorang (Nelson \& Barry, 2005). Hal tersebut sejalan dengan pernyataan bahwa masa remaja dan masa dewasa awal ketika individu berusia 20-an merupakan periode yang memungkinkan berbagai permasalahan lebih banyak muncul, dibandingkan dengan waktu pada fase lainnya (Arnett, 1999).

Salah satu efek yang ditimbulkan dalam ketidakstabilan individu pada tahap perkembangan ini adalah munculnya nilai materialisme yang lebih kuat. Dalam penelitian (Chang \& Arkin, 2002) diketahui bahwa berbagai nilai materialistik pada umumnya dilibatkan dan bahkan diperkuat dalam proses pembentukan identitas dan peran yang lebih jelas dengan individu lainnya pada fase dewasa awal ini. Sebagai contoh, dewasa awal menggunakan barang yang berharga sebagai cara mereka dalam memperjelas identitas dirinya (Chang \& Arkin, 2002) dan sebagai cara untuk menjaga kedekatan dengan individu lain. Pada dewasa awal juga menggunakan harta berharga dan materi untuk mengelola kondisi psikologis mereka yang tidak menyenangkan yang dapat menyebabkan individu terpengaruh materialisme dari lingkungan pada tahap perkembangan ini.

Materialisme sendiri secara umum didefinisikan sebagai perbedaan individu akibat peristiwa hidup yang penuh dengan tekanan (Jiang dkk., 2015). Hal tersebut sebagian terjadi akibat kesalahan persepsi bahwa dengan memiliki barang yang diinginkan dapat secara dramatis merubah cara pandang dan hubungan individu lain terhadap dirinya serta sejauh mana mereka merasa bahagia dalam hidupnya (Richins, 2017). Mengingat bahwa motivasi individu dalam mencari identitas dewasa, keterkaitan, dan kondisi hidup yang diinginkan di saat dewasa awal, maka menjadi hal yang masuk akal untuk mengasumsikan bahwa dalam dukungannya terhadap nilai, tujuan, dan keyakinan bahwa pentingnya memperoleh uang dan harta benda merupakan inti dari penyampaian status kepada individu lain (Hurst dkk., 2014). Terdapat berbagai macam faktor psikologis yang berkorelasi dengan materialisme karena materialisme memiliki potensi implikasi yang negatif bagi individu maupun masyarakat. Misalnya, individu dengan tingkat materialisme yang tinggi akan cenderung memiliki kesejahteraan diri yang rendah (Dittmar dkk., 2014), memiliki hutang keuangan yang lebih besar (Gardarsdóttir \& Dittmar, 2012), dan kurang peduli dengan masalah lingkungan (Hurst dkk., 2013).

Selain beberapa faktor diatas, terdapat salah satu aspek yang menjadi prediktor yang unik dan penting terhadap intensitas terhadap keyakinan dan perilaku materialisme, yakni aspek deprivasi relatif individu. Deprivasi relatif individu mengacu pada rasa ketidakpuasan dan marah yang dihasilkan dari kesadaran bahwa terjadi kesenjangan antara kenyataan dan harapan yang dimiliki oleh seorang individu dibandingkan dengan apa yang dimiliki orang lain (Crosby, 1976; Smith dkk., 2012; Smith \& Pettigrew, 2014). Pengalaman deprivasi relatif pada individu berasal dari proses ketika seorang individu membuat perbandingan sosial mengenai suatu hasil, dimana individu tersebut percaya bahwa telah dirugikan secara tidak adil dan akibatnya ia merasa marah dan tidak puas (Smith dkk., 2012). Salah satu aspek kunci dari proses ini adalah bahwa penilaian secara komparatif dari status seorang individu, bukan hanya status objektif atau absolut, dapat menimbulkan rasa ketidakadilan dan marah. Misalnya, ketika seorang individu mengetahui bahwa ada rekan kerjanya menghasilkan pekerjaan yang sama dengannya tetapi rekan kerjanya mendapatkan gaji yang lebih besar, maka dapat menimbulkan rasa ketidakadilan dan kebencian, meskipun mungkin individu tersebut tidak secara "objektif" terdeprivasi dalam hal pendapatan absolutnya. Sehingga, bagi individu yang kaya secara finansial pun bisa merasa marah dengan nasib hidup mereka, sedangkan bagi individu yang memiliki sumber keuangan yang minim kemungkinan juga tidak selalu merasa dirugikan secara tidak adil (Crosby, 1976) 
Beberapa penelitian telah menunjukkan bahwa aspek status sosial ekonomi yang lebih rendah juga berkaitan dengan tingginya materialisme pada individu (Chang \& Arkin, 2002; Kasser dkk., 1995; J. W. Zhang dkk., 2016). Kasser dkk. (2004) mengemukakan alasan mengapa hal tersebut dapat terjadi karena beberapa individu yang secara sosio ekonomi kurang beruntung memiliki kemungkinan untuk mengkompensasi perasaan atas ketidakcukupan atau ketidakamanan mereka dengan cara mengadopsi nilai dan tujuan materialistis. Namun, individu yang merasa bahwa ia secara relatif terdeprivasi, terlepas dari kedudukan material absolut mereka, juga dapat mementingkan bagaimana cara mendapatkan uang dan harta benda untuk mengimbangi.

Perasaan benci atau marah ketika individu mendapatkan sesuatu yang kurang dari apa yang seharusnya didapatkan jika dibandingkan dengan individu lainnya, dapat dimaknai bahwa kebencian atau rasa marah yang berasal dari perbandingan sosial yang tidak diinginkan memiliki kemungkinan untuk membuat beberapa individu berorientasi pada materialisme, bahkan jika individu tersebut secara objektif dikategorikan kaya. Analisis tersebut sejalan dengan penelitian yang menunjukkan bahwa membandingkan diri sendiri dengan orang lain merupakan hal yang tidak menyenangkan (Callan dkk., 2015), individu sering mengadopsi berbagai strategi untuk meminimalkan perasaan kurang secara relatif (secara relatif terdeprivasi), seperti salah satunya aktivitas gambling atau perjudian (Smith dkk., 2012).

Sebuah studi empiris yang telah dilakukan oleh Smith dkk., (2012) menunjukkan bahwa deprivasi relatif memainkan peran penting dalam banyak proses pribadi dan sosial, mulai dari kesehatan fisik dan mental, hingga sikap terhadap intergroup dan aksi kolektif. Meskipun secara umum deprivasi relatif individu dimaknai sebagai respon situasional terhadap perlakuan kolektif yang tidak adil atau ketidakadilan secara individu, deprivasi relatif juga dapat dipahami sebagai perbedaan individu yang relatif stabil. Beberapa individu, yang belum tentu mereka benar-benar kekurangan (deprivasi), cenderung lebih mengalami deprivasi relatif daripada individu yang lain. Perbedaan seperti itu memang terkait dengan hasil yang berarti. Callan dkk., (2008) menemukan bahwa perbedaan individu dalam deprivasi relatif individu (seperti perasaan bahwa seseorang tidak mendapatkan apa yang pantas didapatkan relatif dengan individu lainnya) menyebabkan perbedaan yang signifikan dalam intensi untuk memunculkan perilaku gambling. Bagi individu yang merasa bahwa dirinya relatif terdeprivasi maka akan lebih banyak melakukan gambling dibandingkan individu yang tidak memliki persepsi tersebut. Berdasarkan uraian di atas, peneliti tertarik untuk mencari tahu hubungan antara deprivasi relatif individu dengan materialisme pada dewasa awal.

\section{Desain Penelitian}

\section{METODE}

Penelitian ini merupakan penelitian kuantitatif, menggunakan sebuah populasi atau sampel tertentu untuk diteliti, dengan metode pengumpulan data berupa survei menggunakan instrument skala penelitian dan menggunakan analisis kuantitatif atau statistik untuk menguji hipotesis yang telah ditentukan (Suryanto, dkk., 2012). Penelitian ini menggunakan tipe Eksplanatori.

\section{Partisipan}

Partisipan penelitian adalah remaja akhir di rentang usia 18-25 tahun. Setelah melakukan proses pengumpulan data berdasarkan kriteria, maka diperoleh partisipan sejumlah 153 orang sesuai dengan data yang dibutuhkan saat mencari minimal sample menggunakan $G$ power. Pengumpulan data dilakukan dalam jaringan (daring) secara sukarela melalui Google Form. 
Partisipan dalam penelitian ini akan menggunakan non probability sampling melalui metode purposive sampling. Responden dalam penelitian ini terdiri dari, perempuan dengan 140 responden atau 91.5\% dan laki-kaki sebanyak 13 respoden atau sebanyak 8.5\%. Rentang usia dari 18 sampai dengan 25 tahun dengan usia terbanyak dalam penelitian ini adalah responden diusia 19 tahun dengan 27 respoden atau $17.6 \%$ dan responden paling sedikit ada direntang usia 25 tahun yang hanya ada 7 responden atau $4.6 \%$.

\section{Pengukuran}

\section{Skala Materialisme}

Material Values Scale (MVS) merupakan alat ukur materialisme yang dikembangkan oleh Richins \& Dawson (1992). Alat ukur materialism memiliki 3 dimensi yaitu success, centrality, happiness. Terdapat 18 aitem dalam skala ini terdiri dari 10 favorable dan 8 aitem unfavorable. Pada skala ini menggunakan butir skala Likert dengan rentang 1 hingga 7. Skor maksimal dari skala ini sebesar 128 dan skor minimal sebesar 18. Skala ini memiliki koefisien reliabilitas yang cukup baik $(\alpha=.703)$.

\section{Skala Deprivasi Relatif Individu}

Deprivasi relatif individu Scale (PRDS) merupakan alat ukur deprivasi relatif yang dikembangkan oleh Callan, dkk (2011). Pada Deprivasi relatif individu Scale (PRDS) memiliki 1 dimensi yaitu belief. Terdapat 5 aitem dalam skala ini terdiri dari 3 aitem favorable dan 2 aitem unfavorable. Pada skala ini menggunakan butir skala Likert dengan rentang 1 hingga 6. Skor maksimal dari skala ini sebesar 30 dan skor minimal sebesar 5 . Skala ini memiliki koefisien reliabilitas yang cukup baik $(\alpha=.728)$.

\section{Analisis Data}

Penulis menggunakan teknik analisa data regresi menggunakan software SPSS 25.0 for windows.

\section{HASIL PENELITIAN}

Hasil survei yang dilakukan oleh peneliti menemukan sebanyak 153 orang sesuai dengan data yang dibutuhkan saat mencari minimal sample menggunakan $G$ power. Responden terdiri dari 140 responden perempuan atau 91.5\% dan laki-kaki sebanyak 13 respoden atau sebanyak 8.5\%. Rentang usia dari 18 sampai dengan 25 tahun dengan usia terbanyak dalam penelitian ini adalah responden diusia 19 tahun dengan 27 respoden atau $17.6 \%$ dan responden paling sedikit ada direntang usia 25 tahun yang hanya ada 7 responden atau $4.6 \%$.

Data deskriptif yang dilakukan oleh peneliti menemukan variable deprivasi relatif $(M=22.35, S D=3.919$ sedangkan untuk variabel materialisme $(M=63.04, S D=11.115)$.

Untuk mengetahui arah dan kekuatan hubungan antar dua variabel, penelitian ini menggunakan teknik analisis korelasi. Hasil analisis uji korelasi tersebut menunjukan bahwa variabel personal relative deprivation berkorelasi positif dan cenderung sedang $(\mathrm{r}(153)=0,360 ; \mathrm{p}=0,000)$ dengan materialisme. Dimana hal tersebut berarti semakin tinggi personal relative deprivation maka materialisme akan semakin tinggi pula begitu juga sebaliknya.

\section{DISKUSI}

Tujuan penelitian ini adalah untuk menguji bagaimana hubungan dari dua variabel berdasarkan hipotesis yang telah dijelaskan sebelumnya yaitu deprivasi relatif personal dan materialisme pada emerging adulthood. Hubungan antara personal relative deprivation dan materialisme pada emerging adulthood diuji dengan menggunakan teknik statistik korelasi pearson product moment yang mana 
memiliki hasil bahwa terdapat hubungan yang signifikan antara personal relative deprivation dan materialisme pada emerging adulthood. Hal tersebut dapat dilihat pada nilai signifikansi hasil uji korelasi memiliki nilai sebesar 0,000 yang lebih kecil dari 0,05. Hal ini sesuai dengan hipotesis awal dimana Ha diterima, sedangkan Ho ditolak.

Dalam Penelitian ini ditemukan bahwa terdapat hubungan positif antara personal relative deprivation terhadap materialisme, yang berarti semakin tinggi personal relative deprivation maka akan semakin tinggi materialisme begitu juga dengan sebaliknya. Hal tersebut terjadi karena individu yang mempunyai perasaan negatif saat membandingkan diri dengan orang lain dalam konteks ini yaitu materialisme. Individu yang meterialistik akan cenderung membandingkan materi yang dia punya dengan orang lain dan mengejar hal-hal yang bersifat meterialistik. Sheldon \& Kesser (2008) mengatakan kepercayaan yang bersifat dasar seperti itu kemudian dapat menyebabkan perasaan uncertainty dan insecurity, yang kemudian dapat berkontribusi pada orientasi ekstrinsik. Sebagai contoh, individu yang mengalami ancaman finansial atau psikologis cenderung lebih menghargai tujuan ekstrinsik seperti uang, penampilan, dan popularitas, dibandingkan dengan tujuan intrinsik seperti proses perkembangan, intimacy, dan komunitas.

Setelah mengetahui hubungan antara personal relative deprivation dan materialisme peneliti melakukan uji tambahan untuk mengetahui bagimana korelasi personal relative deprivation dengan success, happines, dan centrality yang merupakan dimensi dari materialisme. Ditemukan hubungan yang positif dan signifikan antara ketiga dimensi materialisme personal relative deprivation. Hal tersebut terjadi karena uang dan harta benda dikaitkan dengan kesuksesan, kekuasaan, dan status sosial, hal-hal tersebut secara inheren dihargai oleh manusia dari perspektif psikologi evolusioner (Buss, 1995). Namun, individu dengan materialisme yang berlebihan telah dikaitkan dengan penurunan well-being seseorang. Meskipun begitu, masih sangat banyak orang yang tertarik untuk memperoleh lebih banyak harta materi (Gardarsdóttir \& Dittmar, 2012).

Hal ini sejalan dengan penelitian terdahulu yaitu salah satunya penelitian yang telah dilakukan oleh Kim (2017) yang menemukan bahwa responden yang memiliki personal relatif tinggi cenderung membelanjakan lebih banyak untuk hal-hal yang mereka inginkan dibandingkan dengan kategori respoden yang memiliki personal relative deprivation yang rendah. Hal tersebut menunjukan peran personal relative deprivation dalam materialisme terbukti tidak hanya dalam keyakinan, nilai, dan tujuan yang egois, tetapi juga dalam preferensi pengeluaran mereka.

Peneliti lain yang dilakukan oleh Zhang (2015) juga berpendapat bahwa orang-orang yang mempunyai Personal relative deprivation akan sangat peduli tentang menghasilkan uang dan memperoleh harta materi. Jika individu yang relatif kurang mampu memandang diri mereka sendiri sebagai kekurangan sumber daya ekonomi yang mereka inginkan, maka mereka memiliki kecenderungan yang kuat untuk harus memperoleh harta meteri. Dibandingkan dengan orang-orang yang tidak merasa relatif kekurangan, orang-orang yang relatif tidak merasa kekurangan akan lebih menghargai untuk mendapatkan uang dan harta benda. Dapat diketahui bahwa personal relative deprivation mengarah pada materialisme

Materialisme selain dipengaruhi oleh personal relative deprivation juga sering dikaitkan dengan kepribadian dan excessive buying. Dalam penelitian Otero-López \& Villardefrancos (2013) mengatakan materialisme muncul sebagai prediktor utama dari pembelian berlebihan. Tingkat keterbukaan atau keramahan yang rendah dan tingkat ekstraversi yang tinggi meningkatkan nilai materialisme. 
Dalam penelitian ini ditemukan bahwa banyak responden memiliki personal relative deprivation dan materialisme yang sedang, dimana hal ini menjelaskan bahwa memang banyak orang yang memiliki perasaan subjektif terhadap rasa marah, benci, dan frustrasi dalam menanggapi perbandingan sosial negatif dengan orang lain pada emerging adult. Emerging adulthood yang sedang berkembang saat ini dengan penuh semangat merangkul materialisme sebagai nilai yang paling penting dalam hidup mereka. Penelitian yang dilakukan di Program Penelitian Kelembagaan Koperasi di UCLA menyimpulkan bahwa mahasiswa saat ini bekerja keras untuk mendapatkan 'pencapaian finansial' daripada berusaha untuk 'mengembangkan filosofi hidup yang bermakna' seperti yang dilakukan pendahulunya di tahun 1960an (Dreher dkk, 2019). Keinginan seseorang terhadap materi dalam jumlah yang memadai memang diperlukan bagi setiap orang untuk bertahan hidup. Namun, dalam masyarakat yang semakin materialistis, makna uang dan harta benda jauh melampaui kebutuhan hidup (Podoshen dkk., 2011).

\section{SIMPULAN}

Berdasarkan serangkaian analisis yang dilakukan, kesimpulan yang didapatkan dari penelitian ini adalah variabel personal relative deprivation memiliki hubungan yang signifikan dengan materialisme, dimana arah hubungannya adalah positif yang berarti semakin tinggi personal relative deprivation maka materialisme akan semakin tinggi begitu juga dengan sebaliknya.

\section{UCAPAN TERIMAKASIH}

Puji syukur Alhamdulillah kepada Allah SWT karena atas karuniaNya penulis dapat menyelesaikan tugas akhir skripsi sebagai salah satu prasyarat untuk memperoleh gelar Sarjana Psikologi di Universitas Airlangga yang berjudul "Hubungan Antara Personal Relative Deprivation Dengan Materialisme Pada Emerging Adulthood". Dalam penyusunan skripsi ini juga tak lepas dari bantuan dan dukungan dari banyak pihak. Oleh sebab itu, saya mengucapkan terimakasih kepada pihak-pihak yang telah membantu hingga skripsi ini terselesaikan dengan baik.

\section{DEKLARASI POTENSI TERJADINYA KONFLIK KEPENTINGAN}

Indra Wahyu Pratama dan Ilham Nur Alfian tidak bekerja, menjadi konsultan, memiliki saham, atau menerima dana dari perusahaan atau organisasi manapun yang mungkin akan mengambil untung dari diterbitkannya naskah ini.

\section{PUSTAKA ACUAN}

Arnett, J. J. (1999). Adolescent storm and stress, reconsidered. American Psychologist, 54(5), 317-326. https://doi.org/10.1037//0003-066x.54.5.317

Buss, D. M. (1995). Psychological sex differences: Origins through sexual selection. In American Psychologist (Vol. 50, Issue 3, pp. 164-168). https://doi.org/10.1037//0003-066x.50.3.164

Callan, M. J., Ellard, J. H., Will Shead, N., \& Hodgins, D. C. (2008). Gambling as a search for justice: Examining the role of personal relative deprivation in gambling urges and gambling behavior. Personality and Social Psychology Bulletin, 34(11), 1514-1529. https://doi.org/10.1177/0146167208322956 
Callan, M. J., Kim, H., \& Matthews, W. J. (2015). Predicting self-rated mental and physical health: the contributions of subjective socioeconomic status and personal relative deprivation. Frontiers in Psychology. https://doi.org/10.3389/fpsyg.2015.01415

Callan, M. J., Shead, N. W., \& Olson, J. M. (2011). Personal relative deprivation, delay discounting, and gambling. Journal of Personality and Social Psychology, 101(5), 955-973. https://doi.org/10.1037/a0024778

Chang, L. C., \& Arkin, R. M. (2002). Materialism as an Attempt to Cope with Uncertainty. Psychology and Marketing, 19(5), 389-406. https://doi.org/10.1002/mar.10016

Crosby, F. (1976). A model of egoistical relative deprivation. Psychological Review, 83(2), 85-113. https://doi.org/10.1037/0033-295X.83.2.85

Dittmar, H., Hurst, M., Bond, R., \& Kasser, T. (2014). The Relationship Between Materialism and Personal Well-Being: A Meta-Analysis: PERSONALITY PROCESSES AND INDIVIDUAL DIFFERENCES. J Pers $\begin{array}{llr}\text { Soc Psychol, } & \text { 107(5), }\end{array}$ http://ovidsp.ovid.com/ovidweb.cgi?T=JS\&PAGE=reference \&D=paovftp\&NEWS=N\&AN=000052 05-201411000-00007

Dreher, H. M., Smith Glasgow, M. E., \& Schreiber, J. (2019). The use of "high-stakes testing" in nursing education: Rhetoric or rigor? Nursing Forum, 54(4), 477-482. https://doi.org/10.1111/nuf.12363

Gardarsdóttir, R. B., \& Dittmar, H. (2012). The relationship of materialism to debt and financial wellbeing: The case of Iceland's perceived prosperity. Journal of Economic Psychology, 33(3), 471-481. https://doi.org/10.1016/j.joep.2011.12.008

Hurst, M., Dittmar, H., Bond, R., \& Kasser, T. (2013). The relationship between materialistic values and environmental attitudes and behaviors: A meta-analysis. Journal of Environmental Psychology, 36, 257-269. https://doi.org/10.1016/j.jenvp.2013.09.003

Jiang, J., Zhang, Y., Ke, Y., Hawk, S. T., \& Qiu, H. (2015). Can't buy me friendship? Peer rejection and adolescent materialism: Implicit self-esteem as a mediator. Journal of Experimental Social Psychology, 58, 48-55. https://doi.org/10.1016/j.jesp.2015.01.001

Kasser, T., Ryan, R. M., Couchman, C. E., \& Sheldon, K. M. (2004). Materialistic values: Their causes and consequences BT - Psychology and consumer culture: The struggle for a good life in a materialistic world. In Psychology and consumer culture: The struggle for a good life in a materialistic world.

Kasser, T., Ryan, R. M., Zax, M., \& Sameroff, A. J. (1995). The Relations of Maternal and Social Environments to Late Adolescents' Materialistic and Prosocial Values. Developmental Psychology. https://doi.org/10.1037/0012-1649.31.6.907

Kim, H., Callan, M. J., Gheorghiu, A. I., \& Matthews, W. J. (2017). Social comparison, personal relative deprivation, and materialism. British Journal of Social Psychology, 56(2), 373-392. https://doi.org/10.1111/bjso.12176

Nelson, L. J., \& Barry, C. M. N. (2005). Distinguishing features of emerging adulthood the role of self-

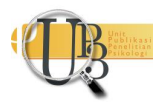


classification as an adult. Journal of Adolescent Research, 20(2), 242-262. https://doi.org/10.1177/0743558404273074

Otero-López, J. M., \& Villardefrancos, E. (2013). Five-Factor Model personality traits, materialism, and excessive buying: A mediational analysis. Personality and Individual Differences, 54(6), 767-772. https://doi.org/10.1016/j.paid.2012.12.013

Podoshen, J. S., Li, L., \& Zhang, J. (2011). Materialism and conspicuous consumption in China: A crosscultural examination. International Journal of Consumer Studies, 35(1), 17-25. https://doi.org/10.1111/j.1470-6431.2010.00930.x

Richins, M. L. (2017). Materialism pathways: The processes that create and perpetuate materialism. Journal of Consumer Psychology, 27(4), 480-499. https://doi.org/10.1016/j.jcps.2017.07.006

Richins, M. L., \& Dawson, S. (1992). A consumer values orientation for materialism and its measurement: Scale development and validation. Journal of Consumer Research, 19(3), 303-316. https://doi.org/10.1086/209304

Sheldon, K. M., \& Kasser, T. (2008). Psychological threat and extrinsic goal striving. Motivation and Emotion. https://doi.org/10.1007/s11031-008-9081-5

Smith, H. J., \& Pettigrew, T. F. (2014). The Subjective Interpretation of Inequality: A Model of the Relative Deprivation Experience. Social and Personality Psychology Compass, 8(12), 755-765. https://doi.org/10.1111/spc3.12151

Smith, H. J., Pettigrew, T. F., Pippin, G. M., \& Bialosiewicz, S. (2012). Relative Deprivation: A Theoretical and Meta-Analytic Review. Personality and Social Psychology Review, 16(3), 203-232. https://doi.org/10.1177/1088868311430825

Suryanto, A. M., Herdiana, I., \& Alfian, I. N. (2012). Pengantar Psikologi Sosial. Pusat Penerbitan dan Percetakan Unair.

Zhang, H., Tian, Y., Lei, B., Yu, S., \& Liu, M. (2015). Personal Relative Deprivation Boosts Materialism. Basic and Applied Social Psychology, 37(5), 247-259. https://doi.org/10.1080/01973533.2015.1072090

Zhang, J. W., Howell, R. T., \& Howell, C. J. (2016). Living in wealthy neighborhoods increases material desires and maladaptive consumption. Journal of Consumer Culture. https://doi.org/10.1177/1469540514521085 